\title{
Membrane potential of guinea-pig spermatozoa
}

\author{
T. J. Rink \\ Physiological Laboratory, Downing Street, Cambridge CB2 3EG, U.K.
}

\begin{abstract}
Summary. The membrane potential of guinea-pig spermatozoa was investigated by using the fluorescent dye, diS- $\mathrm{C}_{3}-(5)$. The potential did not vary when $\mathrm{K}$ replaced $\mathrm{Na}$ in the suspending medium, and in a physiological salt solution the resting potential was found to be about $+13 \mathrm{mV}$.
\end{abstract}

Spermatozoa are known to maintain ionic gradients across the plasma membrane, the K concentration being higher inside than out and the Na concentration lower (Quinn, White \& Wirrick, 1965). This outward $\mathrm{K}$ gradient seems to be maintained by a ouabain-sensitive $\mathrm{Na} / \mathrm{K}$ exchange pump of the kind found in almost all animal cells (Quinn \& White, 1967; Durr, Abla \& Mroueh 1972).

There have been attempts to measure sperm membrane potentials with glass microelectrodes but spermatozoa are too small for successful impalement and what was recorded was not a transmembrane potential but a potential due to fixed charges in the sperm contents (Lindeman \& Rikmenspoel, 1971). Recently, fluorescent dyes have been found which can report the membrane potential of cells in suspension (Hoffman \& Laris, 1974; Sims, Waggoner, Wang \& Hoffman, 1974) and this technique has been used in the present study to examine the membrane potential of spermatozoa.

DiS- $\mathrm{C}_{3}-(5)$ has been the most widely used dye and the mechanism by which it reports the potential has been elucidated (Hladky \& Rink, 1976). The dye is a cation which readily permeates cell membranes and the distribution of the free dye in a cell suspension therefore varies with membrane potential, an increase in intracellular negativity increasing dye uptake. The dye binds to membranes and proteins and when it binds to sperm components the excitation and emission spectra from the dye are shifted towards the red by about $20 \mathrm{~nm}$. By selecting wavelengths at which free dye gives a larger signal than bound dye, a decrease in the fluorescent signal from a sperm suspension can be obtained when there is an increase in dye binding. For a given number of spermatozoa in suspension, therefore, a smaller signal represents increased binding and a more negative membrane potential, hyperpolarization, and a larger signal indicates depolarization.

\section{Methods}

Spermatozoa were obtained from the vasa deferentia and epididymides of mature guinea-pigs. They were washed and resuspended, to give a spermatocrit of about $3 \%$, in a physiological saline (pH 7.4) containing (mM): $\mathrm{NaCl}, 140 ; \mathrm{KCl}, 10 ; \mathrm{Na} H e p e s, 5 ; \mathrm{CaCl}_{2}, 1 ;$ dextrose, $10 . \mathrm{K}$ concentration was altered by isotonic substitution of $\mathrm{NaCl}$ for $\mathrm{KCl}$. The experiments were performed at $37^{\circ} \mathrm{C}$; $4 \mu \mathrm{l} 0 \cdot 1 \mathrm{~mm}$-diS-C $\mathrm{C}_{3}-(5)$ in DMSO were added to $2 \mathrm{ml}$ medium and the fluorescence (excitation 620 $\mathrm{nm}$, emission $660 \mathrm{~nm}$ ) was recorded on a pen recorder. A volume $(25-40 \mu 1)$, which was constant for any one experiment, of the sperm suspension was then added and the mixture stirred briefly. After the level of fluorescence had stabilized, $1 \mu l 2$ mm-valinomycin (Sigma) in DMSO was added. This antibiotic makes cell membranes highly and selectively permeable to K. As discussed previously (Hladky \& Rink, 1976) it is difficult to start each experiment with precisely the same initial fluorescence and the results have been plotted after normalization to give an initial dye fluorescence of 100 . This procedure is justified by the linear relationships between dye concentration and fluorescence, and between dye concentration and binding to sperm components.

$\mathrm{Na}$ and $\mathrm{K}$ concentrations in spermatozoa were measured by flame photometry after centrifugation through $\mathrm{Na}$ and $\mathrm{K}$-free (choline) solution containing ${ }^{57} \mathrm{Co}$-labelled EDTA and ${ }^{3} \mathrm{H}_{2} \mathrm{O}$ for determination of extracellular space and total water in the sperm pellet. Correction was then made for the trapped extracellular $\mathrm{Na}$ and $\mathrm{K}$ and the concentrations were expressed as mol/litre of cell water. 


\section{Results and discussion}

The essential findings are shown in Text-fig. 1. The time course of the fall in fiuorescence when the sperm sample was added presumably indicates dye entry into the cells, but the similarity of the amount of reduction over a wide range of external $\mathrm{K}$ concentrations (0-150 mM) was unexpected. This indicates that the membrane potential of the spermatozoon is little affected by gross reciprocal changes in external $\mathrm{Na}$ and $\mathrm{K}$, and that spermatozoa do not have a $\mathrm{K}$-dominated resting potential.

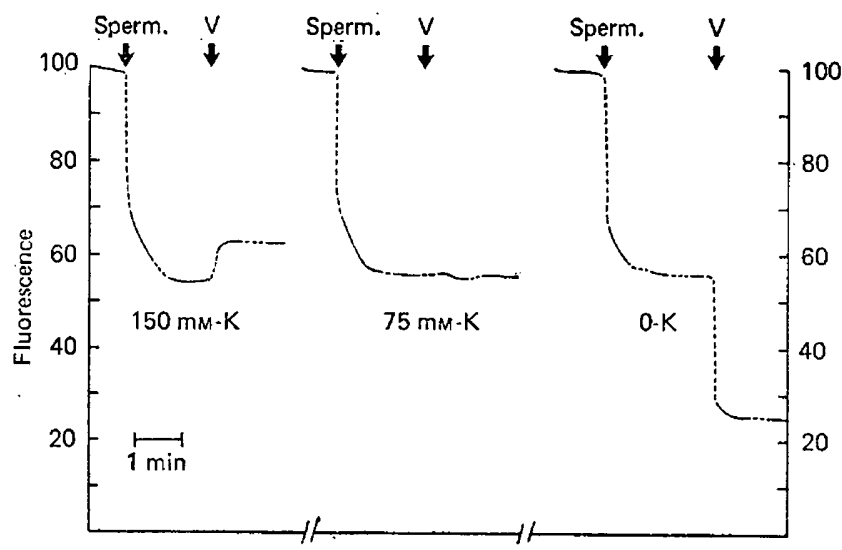

Text-fig. 1. The effect of different concentrations of $\mathrm{K}$ on the fluorescent signal from suspensions of guineapig spermatozoa ( $5 \times 10^{6}$ cells) with $0 \cdot 2 \mu \mathrm{M}$-diS- $\mathrm{C}_{3}-(5)$ before and after addition $(\mathrm{V})$ of $1 \mu \mathrm{mol}$ valinomycin/ litre. The breaks in the tracings indicate stirring.

That the spermatozoa still had intact plasma membranes was shown by examination with Nomarski differential interference-contrast microscopy; most of the spermatozoa appeared normal and many were motile. The addition of valinomycin produced quite different effects on the fluorescent signal at the different $\mathrm{K}$ concentrations. As expected for $\mathrm{K}$-containing cells the fluorescence decreased when $K$ was not present in the suspending medium, indicating hyperpolarization, and increased in 150 $\mathrm{mm}-\mathrm{K}$, indicating depolarization. In the medium containing $75 \mathrm{~mm}-\mathrm{K}$ there was little change after addition of valinomycin, showing that the original resting potential was close to the $\mathrm{K}$ equilibrium potential. A valinomycin 'null point' of this kind was found for $75 \mathrm{~mm}-\mathrm{K}$ with spermatozoa from four different animals, whereas there was hyperpolarization in $50 \mathrm{~mm}-\mathrm{K}$ and depolarization in $112 \mathrm{~mm}-\mathrm{K}$. The membrane potential of spermatozoa in these solutions, which have a similar total $\mathrm{Na}$ and $\mathrm{K}$ concentration to that in rat uterine fluid (Howard \& Defeo, 1959), can therefore be given by:

$$
E_{m}=\frac{R T}{F} \log \frac{75}{K_{\ell}}
$$

where $K_{t}$ is the internal $\mathrm{K}$ concentration (assuming equal activity coefficients inside and out). The $K_{t}$ in seven determinations was $45.4 \pm 5.4$ (S.E.M.) mmol/litre cell water, which gives a potential of $+13 \mathrm{mV}$. The reliability of this value obviously depends on the reliability of the measurement of $K_{t}$. It is also possible that $\mathrm{K}$ is not uniformly distributed throughout the spermatozoon and the same could be true for the membrane potential.

The Na was very low in these spermatozoa, varying from $2-3 \mathrm{mmol} / \mathrm{litre}$ cell water for freshly obtained spermatozoa to $12 \mathrm{mmol} /$ litre after $2 \mathrm{~h}$ in the physiological medium, indicating the presence of a powerful Na pump. The existence of such a pump is further suggested by substantial $\mathrm{K}$ loss and $\mathrm{Na}$ gain after incubation in K-free medium containing $10^{-5} \mathrm{M}$-ouabain.

Preliminary observations did not reveal any substantial effect of different $K$ concentrations on the motility of the spermatozoa, and changes in potential caused by addition of valinomycin did not seem to affect motility. When the membrane was hyperpolarized or depolarized in the presence of $1 \mathrm{mM}-\mathrm{Ca}$ 
there was no discharge of the acrosome, although addition of the Ca ionophore, A23187 (5 $\mu \mathrm{M}$ ), triggered the acrosome reaction in most of the spermatozoa (Green, 1976). It is possible that in spermatozoa the $\mathrm{Ca}$ entry required to discharge the acrosome results from binding of a ligand to the plasma membrane opening a $\mathrm{Ca}$ channel, rather than depolarization promoting $\mathrm{Ca}$ entry through a potential-dependent channel as in many excitable and secretory cells.

This work was supported by Grant GR/A/1698/2 from the Science Research Council. I thank Dr A Waggoner for the gift of diS-C $\mathrm{C}_{3}-(5)$, Dr R. Hamill, Eli Lilly, for the gift of A23187, and Dr D. P. L. Green for helpful discussion.

\section{References}

Durr, I.F., AblA, A. \& Mrourh, A. (1972) ATPase of human spermatozoa. J. Reprod. Fert. 31, 313-316.

GrERN, D.P.L. (1976) Induction of the acrosome reaction in guinea-pig spermatozoa in vitro by the Ca ionophore A23187. J. Physiol., Lond. 260, 18-19P.

HLADKy, S.B. \& RINK, T.J. (1976) Potential difference and the distribution of ions across the human red blood cell membrane: a study of the mechanism by which the fluorescent cation diS- $\mathrm{C}_{3}-(5)$ reports membrane potential. J. Physiol., Lond. 263, 287319.

HOFFMAN, J.F. \& LARIS, P.C. (1974) Determination of membrane potentials in human and amphiuma red blood cells by means of a fluorescent probe. $J$. Physiol., Lond. 239, 519-552.

Howard, E. \& DEFEo, V.J. (1959) Potassium and sodium content of uterine and seminal vesicle secretion. $A m$. J. Physiol. 196, 65-68.

LINDEMAN, C. \& RiKMENSPOEt, R. (1971) Intracellular potentials in bull spermatozoa. J. Physiol., Lond. 219, 127-138.

QUINN, P.J. \& Whrte, I.G. (1967). Active cation transport in dog spermatozoa. Biochem. J. 104, 328-331.

QUINN, P.J., WhITE, I.G. \& WIRRICK, B.R. (1965) Studies of the distribution of the major cations in semen and male accessory secretion. J. Reprod. Fert. 10, 379-388.

Sims, P.J., Waggoner, A.S., Wang, C.H. \& Hoffman, J.F. (1974) Studies on the mechanism by which cyanine dyes measure membrane potential in red blood cells and phosphatidylcholine vesicles. Biochemistry, N.Y. 13, 3315-3330.

Received 8 March 1977 